\title{
sciendo
}

\section{The Coaches' Efficacy Expectations of Youth Soccer Players with Different Maturity Status and Physical Performance}

\author{
by \\ Iván Peña-González"1, Tomas García-Calvo², Eduardo M. Cervelló1, \\ Manuel Moya-Ramón ${ }^{1}$
}

This study aimed to report possible anthropometrical and physical performance differences between youth soccer players with different maturity status and to report the coaches' expectations, hypothesizing that coaches would expect more from players with advanced maturity. One hundred twenty-two (122) players completed a physical performance battery. Their maturity status was estimated and the coaches' efficacy expectations (CEEs) were assessed. Players with advanced maturation had better physical performance $(F=26.5-73.4 ; p<0.01)$ and their CEEs for strength-related tasks were different according to the maturity status $(F=8.3-10.9 ; p<0.01)$, but not for speed-related tests, nor for their general ability to play soccer. Normalized data showed significant differences between physical performance tests and their respective CEEs within each maturity group, especially in the Post-PHV group. This study confirms the physical advantages of players with advanced maturity while it shows controversial results of how maturation affects the coaches' perceptions and, indirectly, the coaches' identification and selection of talented players.

Key words: self-efficacy, youth, maturation.

\section{Introduction}

Strength and speed-related actions are crucial for soccer players and the evaluation of maximal and explosive strength, as well as the sprint and change of direction ability, are commonly used by coaches in youth academies as talent indicators when identifying and selecting a player at early ages (Asadi et al., 2018). Traditional youth development models usually group young players into 1-year cohorts or categories based on their chronological age, trying to create a fair system for the players. It is assumed that through this aggrupation model there will be a certain degree of anthropometrical and physical equality between participants in the same group which will provide them with the same opportunities of succeeding within the group (Cobley et al., 2009). However, in recent years there has been an increasing interest in how the biological maturation of young players may result in inter-individual differences in anthropometric data and physical performance within an age-group (Meylan et al., 2014) and in how these differences may have an impact on training adaptations (Peña-González et al., 2019; Radnor et al., 2017).

Maturation refers to structural and functional changes in young players' bodies during growth. The increase of muscle size or changes in the fiber-type composition, as well as changes in fascicles and tendons, are some examples of how maturation has an impact on strength and speed-related performance in youth soccer players (Radnor et al., 2018). For this reason, players with an advanced maturity status are usually taller, heavier and with greater values of physical performance (i.e. jumping, sprinting or changing of direction abilities) (Asadi et al., 2018; Meylan et al., 2014; Peña-González et al., 2019; Radnor et al., 2017). Information about the

1 - Sport Sciences Department, Miguel Hernandez University, Av. De la Universidad s/n, 03205, Elche, Spain.

2 - Faculty of Sport Science, University of Extremadura. Av. de la Universidad, s/n, 10003. Cáceres (Extremadura), Spain. 
maturity status of youth soccer players may allow coaches and trainers to differentiate between them when the higher level of physical performance of a player may be considered as talent or only as a "temporal" advantage produced by an advanced maturity status (Beunen and Malina, 2008). The most commonly used indicator to assess the somatic maturation is the maturity offset, proposed by Mirwald et al. (2002). This indicator estimates the years from/to the Peak Height Velocity (PHV), which provides a landmark of the maximum growth velocity in height during adolescence (Mirwald et al., 2002; Sherar et al., 2005). The PHV usually occurs at 12 years of age in girls and at 14 years of age in boys, and the estimation of the years from/to the PHV is especially accurate in boys from 12 to 16 years of age (Malina and Kozieł, 2014).

In the practical field, most soccer academies and clubs base their talent identification and selection process on their coaches and scouts' ability to detect those players with the potential to succeed at early ages (Christensen, 2009) with the aim of maximizing the players' performance in the future (Jiménez and Pain, 2008). In this sense, one of the main attributes which coaches and scouts take into account to identify a talented player and to select them at an early age is the players' anthropometric data and physical performance (Carling et al., 2009). However, this players' selection normally is based on coaches or scouts' "eye", "perceptions" or "practical sense" (Christensen, 2009). Specifically, the perception coaches and scouts have of their players is assessed through the coaches' efficacy expectations (CEEs) which reflect the degree of confidence of coaches in their players' abilities, capacities and skills regarding the requirements to perform specific tasks (Leo et al., 2013). The coaches beliefs have been traditionally linked to a bias related to the talent identification process called "the self-fulfilling prophecy" which was described by Merton (1948). Under this perspective, the greater the coach's expectation placed on an individual, the greater the result that an individual will attain. This effect explains the coaches' attitudes and their decisions which are based on their previous expectations placed on players (Hancock et al., 2013). Thus, if a coach expects more from a player with advanced maturation, it would be expected that this player receives more attention from the coach and is selected to a greater extent than his peers with delayed maturation.

However, although previous research showed that physical performance may be different between players with different maturity status (Malina et al., 2005; Peña-González et al., 2019), no previous studies have analyzed the impact of the maturity-related differences between young soccer players on the CEEs. Thus, the aims of this study were (1) to report the possible anthropometrical and physical performance differences between players with different maturity status in strength and speedrelated, actions and (2) to report the coaches' efficacy expectations in each maturity group, hypothesizing that coaches would expect more in the physical performance test as well as in general performance in soccer from players with an advanced maturity status.

\section{Methods}

\section{Participants}

One hundred and twenty-two U13 to U15 male soccer players from the first and second Spanish competition levels and their coaches participated in the study. Data information about players is shown in Table 1. All players pertained to the same academy and they competed in the Spanish first and second level of competition (national and regional levels). Players had a minimum of six years' experience in federated practice. Coaches of the teams that were evaluated $(\mathrm{n}=8)$ participated by completing a questionnaire regarding their expectations about their players. All coaches had a minimum of ten years' coaching experience and they had the pertinent license. Players and coaches took part voluntarily, and they as well as players' parents/guardians were informed about the aims and procedures of the study and written consent was obtained. The study was approved by an Ethics Committee (DPS.EC.01.17) and conformed to the recommendations of the Declaration of Helsinki.

\section{Measures}

Coaches' efficacy expectations (CEEs) were assessed by means of a previously validated questionnaire (Peña-González et al., 2018) created according to the recommendations of Bandura (2006). Coaches answered five Likert-questions 
(from 1 to 5) about their confidence in the players' ability to perform each physical test (1RM, PP, 30$\mathrm{m}$ sprint and T-test) and in the players' ability to play soccer (Soccer Performance Expectations, SPE). In Peña-González et al. (2018), the questionnaire showed a single factor between the CCE for the different physical performance tests. This factor was initially defined as Physical Performance Expectations (PP), but was renamed as Physical Condition Expectations (PCE) in the present study to distinguish it from the Peak Power output (PP) performance. In the current study, the Cronbach's alpha of the four items was 0.87. Considering Cronbach's alpha values over 0.70 as acceptable scores, the PCE showed good internal reliability (Nunnally and Bernstein, 1994). Regarding SPE, a single-item was used to measure this variable. Empirical support does exist for the use of singleitem measures, suggesting that they are appropriate for use uner certain circumstances, especially for measuring individual and collective efficacy or performance (Bruton et al., 2016; Jordan and Turner, 2008).

The PHV takes place around 14 years of age in boys and 12 in girls, and it indicates the theoretical point of maximum growth in height during adolescence (Malina et al., 2004). The prediction of the years from/to PHV provides accurate information about the maturity status of the young player (Mirwald et al., 2002; Sherar et al., 2005) being especially accurate in 12 to 16 year-old boys with an "on average" maturation (Malina and Kozieł, 2014). Participants were divided into three maturity groups according to their years from/to PHV which were called Pre- (n $=46 ;<1.0$ years to PHV), Mid- $(\mathrm{n}=60$; between 1.0 year to and 1.0 year from the PHV) and Post-PHV $(\mathrm{n}=16 ;>1.0$ years from PHV).

\section{Design and Procedures}

Anthropometric measurements were carried out under standardized conditions $(20 \pm$ $1^{\circ} \mathrm{C}$ ) inside a laboratory at the beginning of the testing session. Body height and sitting height were measured with a fixed stadiometer $( \pm 0.1 \mathrm{~cm}$, SECA LTD., Germany), and leg length was the result of body height minus sitting height. Body mass was measured with a digital scale $( \pm 0.1 \mathrm{~kg}$, Oregon scientific ${ }^{\circledR}$ GA101/GR101) and the date of birth was registered.

After collecting the anthropometrical measurements, players carried out a warm-up consisting of jogging, dynamic stretching and several squats with different loads. The half-squat one repetition maximum (1RM) and peak power output (PP) were estimated indirectly (GonzálezBadillo and Sánchez-Medina, 2010) using a linear encoder (T-Force System, Ergotech, Murcia, Spain) and performed using a Smith Machine (Technogym Trading, Gambettola, Italy). For the estimation of the $1 \mathrm{RM}$, each player started with approximately $50 \%$ of their $1 \mathrm{RM}$ and the load was increased in the following sets. Players performed a minimum of three sets of three to five repetitions and a maximum of five sets. Based on previous research, for PP analysis, each player performed three maximal velocity repetitions using $60 \%$ of their $1 \mathrm{RM}$ and the maximum value of the power-time curve was recorded (Cormie et al., 2007).

The 30-m sprint in a straight line and the agility T-test (Semenick, 1990) were performed in an outdoor synthetic-grass soccer pitch, and players used soccer boots. A specific warm-up consisting of accelerations, decelerations and changes of direction was performed for ten minutes before the outdoor tests. The time of the $30-\mathrm{m}$ sprint and the agility T-test were measured using photoelectric cells (Witty System, Microgate, Bolzano, Italy) which started a digital timer. Participants started from a standing position, $30-\mathrm{cm}$ behind the photocell and they were encouraged to perform the tests at their maximal effort. Three attempts of each test were performed with two minute rest intervals in between. The time of the best attempt was recorded for further analysis.

\section{Statistical Analysis}

A one-way analysis of variance (ANOVA) was used to compare both, anthropometric data and physical performance according to the maturity group. A secondary ANOVA was used to compare the CEEs between the different maturity groups. The Bonferroni post-hoc test was carried out to analyze the pairwise differences between the three maturity groups in each ANOVA. Effect size (ES) in all variables was calculated with the Cohen's $d$ between Pre- and Post-PHV as trivial $(<0.25)$, small $(0.25-0.50)$, moderate $(0.50-1.0)$, and large (>1.0) (Rhea, 2004). Data for physical performance tests and for CCEs were normalized within each maturity group by means of "Z-scores" ([Player score - Group mean 
score] / SD) (Till et al., 2018). Correlation analysis and a multiple paired sample $t$-test were used to compare each physical performance test with their respective CCE, as well as to compare the CEE of general physical condition (PCE) with the general perception of performance in soccer (SPE). All calculations were carried out using Microsoft Excel (Microsoft, Seattle, Washington, USA) and SPSS Statistics ${ }^{\circledR}$ (Statistical Package for the Social Sciences, Version 17.0), and the level of significance was set at $p<0.05$.

\section{Results}

ANOVA showed statistical differences and large ES in weight and height $\left(\mathrm{F}_{(2,119)}=\right.$ 86.2; $p<0.01$ and $\mathrm{F}(2,119)=121.6 ; p<0.01$, respectively) as well as in the physical performance tests (1RM: $\mathrm{F}_{(2,119)}=73.4 ; p<0.01$; PP: $\mathrm{F}(2,119)=53.4 ; p<0.01 ; 30-\mathrm{m}$ sprint: $\mathrm{F}(2,119)=$ 29.7; $p<0.01$; T-test: $\mathrm{F}(2,119)=26.5 ; p<0.01)$ according to the maturity group. Additionally, CEEs in $1 R M$ and PP tests were significantly different, with moderate ES, between the different maturity groups $\left(\mathrm{F}_{(2,119)}=8.3 ; p<0.01\right.$ and $\mathrm{F}(2,119)=$ $10.9 ; p<0.01$, respectively). The CEEs of speed and change of direction ability ( $30-\mathrm{m}$ sprint and Ttest expectations) did not show significant differences according to the maturity group ( $\mathrm{F}(2$, ${ }_{119)}=2.6 ; p=0.08 ;$ small $\mathrm{ES}$ and $\mathrm{F}(2,119)=1.3 ; p=0.28$; trivial ES, respectively). The post-hoc analysis showed pairwise statistical differences between each maturity group for both, the anthropometric data and for each physical fitness test (Table 2). Descriptive data for anthropometrical and physical performance variables in each maturity group expressed as Mean \pm Standard Deviation as well as the ES between Pre- and Post-PHV were also reported (Table 2), showing Large ES between maturity groups for anthropometric data and physical performance tests. Regarding the CEEs, post-hoc analysis revealed that statistical differences in 1RM and PP expectations only occurred between Pre-PHV and the other maturity groups. No other statistical difference in the 30-m sprint, T-test, PCE or SPE was reported (Table 3). Moderate ES was observed between Preand Post-PHV for 1RM and PP while Small to Trivial ES was reported for the 30-m sprint, the T-test and PCE or SPE.

Correlation analysis and comparison between each physical performance test with its respective CEE within each maturity group are shown in Table 4. PCE correlated with SPE in each maturity group (Pre-PHV: $\mathrm{r}=0.41 ; p<0.01$; MidPHV: $\mathrm{r}=0.71 ; p<0.01$; Post-PHV: $\mathrm{r}=0.81 ; p<$ $0.01)$, and thus, no statistical differences were found between PCE and SPE in any maturity group $(t=0.64-1.80 ; p=0.10-0.52)$.

\begin{tabular}{|c|c|c|c|}
\hline \multicolumn{4}{|c|}{ Players' characteristics } \\
\hline & U13 & U14 & U15 \\
\hline $\mathrm{n}$ & 62 & 39 & 21 \\
\hline Age (yr) & $12.6 \pm 0.4$ & $13.9 \pm 0.4$ & $14.9 \pm 0.5$ \\
\hline Maturity offset (yr) & $-1.18 \pm 0.72$ & $0.06 \pm 0.68$ & $1.23 \pm 0.67$ \\
\hline Weight (kg) & $48.2 \pm 8.8$ & $55.3 \pm 8.0$ & $62.2 \pm 7.1$ \\
\hline Height $(\mathrm{cm})$ & $156.7 \pm 8.6$ & $165.4 \pm 9.0$ & $173.9 \pm 7.2$ \\
\hline \multicolumn{4}{|c|}{ n: sample size } \\
\hline
\end{tabular}




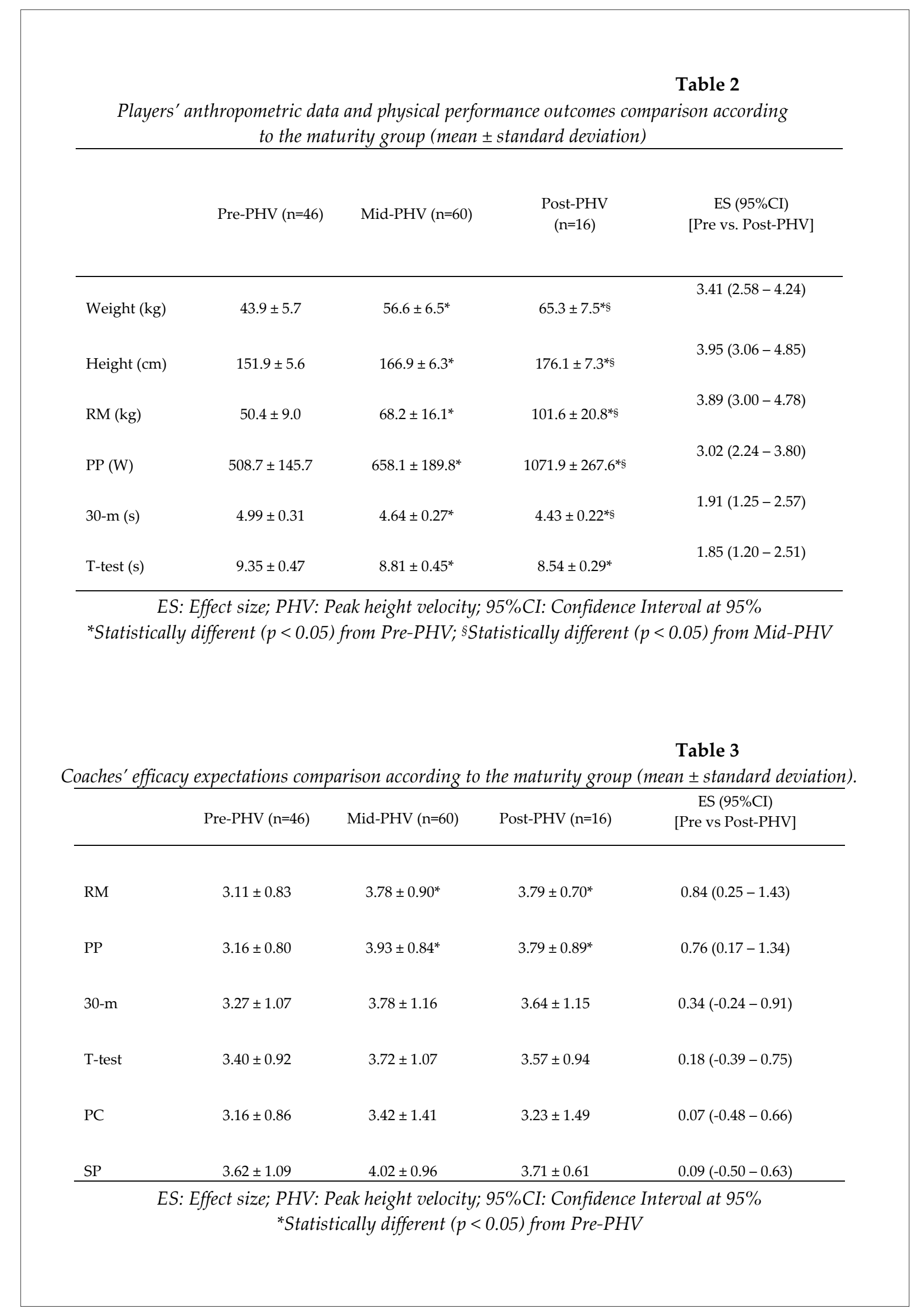


Table 4

Normalized measures of physical performance tests and coaches' efficacy expectations (CEEs) within the different maturity groups

\begin{tabular}{|c|c|c|c|c|c|}
\hline \multirow{2}{*}{ Maturity group } & \multirow{2}{*}{$\begin{array}{l}\text { Physical performance test } \\
\text { vs CEE }\end{array}$} & \multicolumn{2}{|c|}{ Correlation } & \multicolumn{2}{|c|}{ Comparison } \\
\hline & & $\mathrm{r}$ & $p$ & $\mathrm{t}(95 \% \mathrm{CI})$ & $p$ \\
\hline \multirow{4}{*}{ Pre-PHV } & RM & 0.155 & 0.32 & $-1.91(-0.56 ; 0.02)$ & 0.06 \\
\hline & PP & 0.260 & 0.09 & $-0.50(-0.35 ; 0.21)$ & 0.62 \\
\hline & $30-m$ & 0.599 & $<0.01$ & $-3.74(-0.72 ;-0.21)$ & $<0.01$ \\
\hline & T-test & 0.349 & 0.02 & $-3.12(-0.84 ;-0.18)$ & $<0.01$ \\
\hline \multirow{4}{*}{ Mid-PHV } & $\mathrm{RM}$ & 0.103 & 0.45 & $-0.35(-0.44 ; 0.31)$ & 0.73 \\
\hline & PP & 0.117 & 0.40 & $-1.38(-0.57 ; 0.11)$ & 0.17 \\
\hline & $30-\mathrm{m}$ & 0.322 & 0.02 & $1.20(-0.12 ; 0.49)$ & 0.24 \\
\hline & T-test & 0.374 & $<0.01$ & $2.18(0.03 ; 0.65)$ & 0.03 \\
\hline \multirow{4}{*}{ Post-PHV } & RM & 0.001 & 0.99 & $4.12(0.60 ; 1.97)$ & $<0.01$ \\
\hline & PP & 0.220 & 0.49 & $4.26(0.67 ; 2.09)$ & $<0.01$ \\
\hline & $30-\mathrm{m}$ & 0.420 & 0.23 & $2.72(0.13 ; 1.47)$ & 0.02 \\
\hline & T-test & 0.866 & $<0.01$ & $4.06(0.28 ; 0.99)$ & $<0.01$ \\
\hline
\end{tabular}

PHV: Peak height velocity

\section{Discussion}

The present study aimed to evaluate the possible physical performance differences in U13 to U15 Spanish soccer players related to their maturity status, with the coaches' efficacy expectations (CEEs) about their players. To the authors' knowledge, this is the first study which aims to report if the main people responsible for identifying and selecting a young soccer player as talented within a soccer academy are able to distinguish between their maturity-related physical advantages and if their expectations about their players' abilities to play soccer are related to their expectations about their players' physical performance.

Results from this study strengthen the idea that those players with an advanced maturity status have anthropometric and physical performance advantages. Players with an advanced maturity status were taller and heavier and they performed the physical tests better than players with a delayed maturity status. These results are in line with previous research (Cripps et al., 2016; Malina et al., 2005; Peña-González et al., 2019) which reported anthropometric and physical performance differences between players with different maturity status, favoring those with advanced maturation. A combination of structural and neuromuscular changes throughout the maturation process are detailed by Radnor et al. (2018) as the main responsible factors for an increase in the stretch-shortening cycle which appears in most of the soccer strength and speed- 
related actions such as sprinting, jumping or kicking.

However, no systematic differences for CEEs were found between maturity groups. CEEs were significantly lower for less mature players (Pre-PHV) in 1RM and PP tests. No statistical differences were found between Mid- and PostPHV for these tests nor was any other difference found in CEEs for the 30-m sprint or the T-test. In addition, normalized data showed significant differences between physical performance in tests and their respective CEE. The authors hypothesized that coaches would be able to detect the physical advantage of more-mature players and that they would expect more from them in physical performance tests, based on previous research which reported that coaches' perceptions about their players may be biased by their maturity status (Cripps et al., 2016; Romann et al., 2017). However, coaches in this study only detected the physical disadvantage of less-mature players in strength-related abilities such as maximal and power strength. These results are in contrast with the traditional perception that coaches base their physical expectations on biological characteristics, rather than on chronological age (González-Víllora et al., 2015). From this perspective, more mature players would be identified as talented ones and be selected to a greater extent due to these temporal physical advantages than players delayed in their maturation (Meylan et al., 2010; Pearson et al., 2006). Nevertheless, the CEEs of this study were significantly different from the results of the physical performance tests, especially in the PostPHV group, and they did not seem to be able to detect the physical performance advantage in players with advanced maturation (Table 2). This fact contrasts with the general idea that more mature players are perceived by coaches and scouts as better performers in physical actions than their less mature peers and also contrasts with the theories about how they will be selected to a greater extent due to this fact, leaving players with delayed maturity out from the selection process (Vaeyens et al., 2008). Accordingly, soccer coaches from this study did not perceive greater general physical condition (PCE) in players with advanced maturation. According to the traditional explanation of the talent identification and selection process, the coaches' expectations of soccer performance (SPE) about their players would be greater for players with advanced maturation due to both anthropometric and physical performance advantages together with a greater perception of strength-related performance. Cripps et al. (2016) observed how coaches in Australian Football perceived players with advanced maturation as technically better, but no significant differences were found between maturity groups. It could be considered as a support to the idea of a better perception of coaches for players with an advanced maturity status. Nevertheless, results in the present study about SPE did not show differences between different maturity groups. These results indicate that coaches actually do not expect more from players with an advanced maturity status. Coaches' SPE from their players may be based on other characteristics rather than only on physical attributes (Williams and Reilly, 2000). In this regard, Christensen (2009) indicated the main characteristics which coaches should take into account to identify a talented player in soccer. Three important findings from this model such as (1) coaches use their "practical sense" or "expert eye" to identify talent, (2) the coaches' preference for the "autotelic players" or players who have potential to learn, practice and improve (rather than other attributes than physical performance or technical and tactical abilities), and (3) the coaches' predilection may modify the main attributes to be taken into account in each context (Christensen, 2009), may explain the results of the current study. However, the normalized data showed no significant differences and a strong correlation between PCE and SPE in each maturity group. It reveals that coaches also consider those players who they believe to be better "physical performers" as "better soccer players".

Talent identification and selection programs are crucial in soccer academies to select players with the potential to succeed in the future and provide them with specialized training (Unnithan et al., 2012). This process should be dynamic and multifactorial, with an objective assessment of physical performance and maturity status throughout childhood and adolescence, which complement the coaches' perceptions or "practical sense" and help them take the final decision about the players' selection and/or 
promotion within an academy or a soccer club.

The present study includes some limitations which should be considered to interpret the results. First, coaches and players of this study affirmed they were familiarized with strength-related exercises (i.e., squat with external loads), but in future research, the years of strength training experience of players could be registered to ensure they are highly familiarized with this kind of evaluations (i.e. 1RM or PP) and to ensure that differences between groups are not related to different training experience or learning effect. In addition, although the most common method was used to divide players between groups according to their maturity status (having the maturity cutoff points in \pm 1.0 ), other methods have been observed in the literature (i.e. having the maturity cut-off points in \pm 0.5 instead of \pm 1.0 or creating groups with the same number of participants, being the maturity cut-off points random).

As a conclusion, the present study, in agreement with previous research, confirms that youth soccer players with an advanced maturity status have anthropometric and physical performance advantages compared to their peers with delayed maturation. The main contribution of this study is that coaches were not able to perceive the general physical advantage of young players with advanced maturation. Soccer coaches were able to detect differences in strength-related tests between players who had not reached their $\mathrm{PHV}$ and players who were around or had passed their PHV. However, coaches did not perceive the actual differences in sprint and change of direction ability of players with different maturity status, nor did they perceive a general physical performance advantage. In addition, coaches did not expect more from players with advanced maturity in their general ability to play soccer as authors had hypothesized. Both the anthropometric and physical performance evaluation, as well as the coaches' perceptions, have been traditionally studied in talent identification and selection programs, but maturity status may influence physical attributes, biasing the results. More research about how the players' maturity status affects the coaches' perceptions is needed.

\section{References}

Asadi A, Ramirez-Campillo R, Arazi H, Sáez de Villarreal E. The effects of maturation on jumping ability and sprint adaptations to plyometric training in youth soccer players. J Sports Sci., 2018; 36(21): 24052411. https://doi.org/10.1080/02640414.2018.1459151

Beunen G, Malina RM. Growth and Biologic Maturation: Relevance to Athletic Performance. The Young Athlete. Blackwell Publishing Ltd., 3-17; 2008 https://doi.org/10.1002/9780470696255.ch1

Bruton AM, Mellalieu SD, Shearer DA. Validation of a single-item stem for collective efficacy measurement in sports teams. Int $J$ Sport Exerc Psychol., 2016; 14(4): 383-401. https://doi.org/10.1080/1612197X.2015.1054853

Carling C, Le Gall F, Reilly T, Williams AM. Do anthropometric and fitness characteristics vary according to birth date distribution in elite youth academy soccer players? Scand J Med Sci Sports., 2009; 19(1): 3-9. https://doi.org/10.1111/j.1600-0838.2008.00867.x

Christensen MK. "An eye for talent": Talent identification and the "practical sense" of top-level soccer coaches. Sociol Sport J., 2009; 26(3): 365-382. https://doi.org/10.1123/ssj.26.3.365

Cobley S, Baker J, Wattie N, Mckenna J. Annual age-grouping and athlete develop- ment. A metas-analytical review of relative age effects in sport. Sports Med., 2009; 39(39): 235-256.

Cormie P, Mccaulley GO, Triplett NT, Mcbride JM. Optimal loading for maximal power output during lower-body resistance exercises. Med Sci Sports Exerc., 2007; 39(2): 340-349. https://doi.org/10.1249/01.mss.0000246993.71599.bf

Cripps AJ, Hopper L, Joyce C. Maturity, physical ability, technical skill and coaches' perception of semi-elite adolescent australian footballers. Pediatr Exerc Sci., 2016; 28(4): 535-541. https://doi.org/10.1123/pes.2015-0238

González-Badillo JJ, Sánchez-Medina L. Movement velocity as a measure of loading intensity in resistance training. Int J Sports Med., 2010; 31(05): 347-352. https://doi.org/10.1055/s-0030-1248333 
González-Víllora S, Pastor-Vicedo JC, Cordente D. Relative age effect in UEFA Championship soccer players. J Hum Kinet., 2015; 47(1): 237-248. https://doi.org/10.1515/hukin-2015-0079

Hancock DJ, Adler AL, Côté J. A proposed theoretical model to explain relative age effects in sport. Eur J Sport Sci., 2013; 13(6): 630-637. https://doi.org/10.1080/17461391.2013.775352

Jiménez IP, Pain MTG. Relative age effect in Spanish association football: its extent and implications for wasted potential. J Sports Sci., 2008; 26: 995-1003. https://doi.org/10.1080/02640410801910285

Jordan JS, Turner BA. The feasibility of single-item measures for organizational justice. Meas Phys Educ Exerc Sci., 2008; 12(4): 237-257. https://doi.org/10.1080/10913670802349790

Leo FM, Sánchez-Miguel PA, Sánchez-Oliva D, Amado D, García-Calvo T. Analysis of cohesion and collective efficacy profiles for the performance of soccer players. J Hum Kinet., 2013; 39(1): 221-229. https://doi.org/10.2478/hukin-2013-0085

Malina RM, Bouchard C, Bar-Or O. Growth, maturation, and physical activity. Champaign, IL: Human Kinetics Books; 2004.

Malina RM, Cumming SP, Kontos AP, Eisenmann JC, Ribeiro B, Aroso J. Maturity-associated variation in sport-specific skills of youth soccer players aged 13-15 years. J Sports Sci., 2005; 23(5): 515-522. https://doi.org/10.1080/02640410410001729928

Malina RM, Kozieł SM. Validation of maturity offset in a longitudinal sample of Polish boys. J Sports Sci., 2014; 32(5): 424-437. https://doi.org/10.1080/02640414.2013.828850

Merton RK. The Self-Fulfilling Prophecy. Antioch Review, 1948; 8(2): 193-210

Meylan C, Cronin JB, Oliver JL, Hopkins WG, Contreras B. The effect of maturation on adaptations to strength training and detraining in 11-15-year-olds. Scand J Med Sci Sports., 2014; 24(3): 156-164. https://doi.org/10.1111/sms.12128

Meylan C, Cronin J, Oliver J, Hughes M. Talent identification in soccer: The role of maturity status on physical, physiological and technical characteristics. Int J Sports Sci Coach., 2010; 5(4): 571-592. https://doi.org/10.1260/1747-9541.5.4.571

Mirwald RL, Baxter-Jones ADG, Bailey D. Beunen GP. An assessment of maturity from anthropometric measurements. Med Sci Sports Exerc., 2002; 34(4): 689-694. https://doi.org/10.1097/00005768-20020400000020

Nunnally J, Bernstein I. Psychometric theory. Auflage, New York: Mc Graw-Hill; 1994

Pearson DT, Naughton GA, Torode M. Predictability of physiological testing and the role of maturation in talent identification for adolescent team sports. J Sci Med Sport., 2006; 9(4): 277-287. https://doi.org/10.1016/j.jsams.2006.05.020

Peña-González I, Fernández-Fernández J, Cervelló E, Moya-Ramón M. Effect of biological maturation on strength-related adaptations in young soccer players. PLoS One., 2019; 14(7), e0219355. https://doi.org/10.1371/journal.pone.0219355

Peña-González I, Fernández-Fernández J, Moya-Ramón M, Cervelló E. Relative age effect, biological maturation, and coaches' efficacy expectations in young male soccer players. Res Q Exerc Sport., 2018; 89(3), 373-379. https://doi.org/10.1080/02701367.2018.1486003

Radnor JM, Lloyd RS, Oliver JL. Individual response to different forms of resistance training in school-aged boys. J Strength Cond Res., 2017; 31(3): 787-797. https://doi.org/10.1519/JSC.0000000000001527

Radnor, JM, Oliver JL, Waugh CM, Myer GD, Moore IS, Lloyd RS. The influence of growth and maturation on stretch-shortening cycle function in youth. Sports Med., 2018; 48(1): 57-71. https://doi.org/10.1007/s40279-017-0785-0

Rhea MR. Determining the magnitude of treatment effects in strength training research through the use of the effect size. J Strength Cond Res., 2004; 18(4): 918

Romann M, Javet M, Fuchslocher J. Coaches' eye as a valid method to assess biological maturation in youth elite soccer. Talent Dev Excell., 2017; 9(1): 3-13

Semenick D. Tests and measurements: The T-test. Strength Cond J., 1990; 12(1)

Sherar LB, Mirwald RL, Baxter-Jones ADG,Thomis M. Prediction of adult height using maturity-based cumulative height velocity curves. J Pediatr, 2005; 147(4): 508-514. https://doi.org/10.1016/j.jpeds.2005.04.041 
Till K, Morris R, Emmonds S, Jones B, Cobley S. Enhancing the evaluation and interpretation of fitness testing data within youth athletes. Strength Cond J., 2018;40(5): 24-33. https://doi.org/10.1519/SSC.0000000000000414

Unnithan V, White J, Georgiou A, Iga J, Drust B. Talent identification in youth soccer. J Sports Sci., 2012; 30(15): 1719-1726. https://doi.org/10.1080/02640414.2012.731515

Vaeyens R, Lenoir M, Williams AM, Philippaerts RM. Talent identification and development programmes in sport current models and future directions. Sports Med, 2008; 38(9): 703-714. https://doi.org/10.2165/00007256-200838090-00001

Williams AM, Reilly T. Talent identification and development in soccer. J Sports Sci., 2000; 18: 657-667. https://doi.org/10.1080/714004845

\section{Corresponding author:}

\section{Manuel Moya-Ramón}

Sport Research Center, Miguel Hernández University of Elche.

Av. De la Universidad s/n, 03202, Elche, Spain.

Department of Sport Sciences

Tel: +34 965222046

E-mail: mmoya@umh.es 